\title{
Hasat Sonrası UV-C Uygulamalarının Giant Erik Çeşidinin Meyve Kalitesi ve Soğukta Muhafazası Üzerine Etkileri
}

\author{
Erdinç $\mathrm{BAL}^{1}$ \\ Salih ÇELIK ${ }^{1}$ \\ Geliş Tarihi: 10.09.2007 \\ Kabul Tarihi: 10.06 .2008
}

\begin{abstract}
Öz : Bu çalışmanın amacı, farklı dozdaki UV-C ışın uygulamalarının Giant Erik çeşidinin meyve kalitesi ve soğukta muhafaza süresi üzerine etkinliğinin belirlenmesidir. Meyvelere 50 ve $100 \mathrm{~cm}$ mesafeden 5,10 ve 20 dakika süre ile ışın uygulaması yapıldıktan sonra $750 \mathrm{~g}$ 'lık kaplar içerisinde polietilen torbalar ile ambalajlanmıştır. Tüm paketler $0-1^{\circ} \mathrm{C}$ sıcaklık ve $\% 90 \pm 5$ nispi neme sahip depoda 5 hafta süre ile muhafaza edilmiştir. Soğukta muhafaza süresince haftalık olarak meyve örneklerinde ağırlık kaybı, meyve sertliği, suda çözünür kuru madde miktarı, titre edilebilir asitlik miktarı, suda çözünür kuru madde miktarı / titre edilebilir asitlik miktarı oranı, $\mathrm{pH}$ ve duyusal (tat ve görünüş) analiz ölçümleri yapılmıştır. Muhafaza süresince uygulamalara göre değişmekle birlikte genel olarak ağırlık kayıpları ve suda çözünür kuru madde miktarı artmış, meyve eti sertliği ve titre edilebilir asitlik miktarı ise azalmıştır. Araştırmada, 35. gün sonunda kalite kayıpları en çok 100 $\mathrm{cm} 5$ dak ve 20 dak UV-C dozu ile kontrol grubunda görülmüş, en iyi sonuçlar ise $50 \mathrm{~cm} 5$ dak ve 10 dak UV-C dozunda belirlenmiştir.
\end{abstract}

Anahtar Kelimeler: Erik, UV-C uygulaması, muhafaza, kalite

\section{Effects of Postharvest UV-C Treatments on Quality and Cold Storage of cv. Giant Plum}

\begin{abstract}
The aim of this study is to determine effectiveness of different UV-C treatments on fruit quality and cold storage period of cv. Giant plum. After fruits were treated UV-C from 50 and $100 \mathrm{~cm}$ distance for 5,10 and $20 \mathrm{~min}$, they were placed in container $(750 \mathrm{~g})$ and packed with polyethylene bag. All packages were stored at $0-1^{\circ} \mathrm{C}$ and $90 \pm 5 \%$ relative humidity for 5 weeks. During the storage period, weight loss, fruit firmness, soluble solids content, titretable acidity, soluble solids content / titretable acidity, fruit juice $\mathrm{pH}$ and sensorial (taste and appearance) analyze measurements in fruit samples were performed at 1 week interval. Although it changed according to treatments, weight loss and soluble solids content generally increased; fruit firmness and titretable acidity decreased in the course of storage period. In the research, the highest quality losses were observed in UV-C treatment from $100 \mathrm{~cm}$ distance for $5,20 \mathrm{~min}$ and control at the end of 35 days, the best results were obtained from UV-C treatment from $50 \mathrm{~cm}$ for 5 and $10 \mathrm{~min}$.
\end{abstract}

Key Words: Plum, UV-C treatment, storage, quality

\section{Giriş}

Ülkemizde toplam meyve üretimimiz içerisinde erik üretimimiz 215.000 tonla önemli bir yer tutmaktadır (Anonymous 2005). Son yıllarda yüksek vitamin içeriği, lif ve antioksidan madde içeriği ile erik yetiştiricilikte ön plana çıkan meyvelerden biridir (Kim ve ark. 2003). Genel olarak, Türkiye'de sert çekirdekli meyvelerin muhafazasına ilişkin çalışmalar, yumuşak çekirdekli meyvelerin muhafazasına ilişkin çalışmalardan daha sonra dikkate alınmıştır (Eriş 2001). Bu yüzden sert çekirdekli meyve türlerinde de derim sonrasına ilişkin çalışmalara yer verilmesi gerekmektedir.
Erik meyveleri genellikle depolarda çok fazla saklanmaz. Ancak, kısa sürede pazara fazla meyve gönderme zorunluluğunun olduğu durumda, fiyat düşmelerini önlemek için meyvelerin bir kısmının soğuk hava depolarında saklanması yararlı olmaktadır (Özçağıran ve ark. 2003).

Erik klimakterik bir meyvedir ve çeşide bağlı olarak 1-8 hafta arasında muhafaza ömrüne sahip çabuk bozulabilen bir meyve türüdür (Perez-Gago ve ark. 2003). Türk ve ark. (1995) Giant erik çeşidini modifiye atmosferli ambalajlama ile 20 gün süre ile muhafaza edebilmişlerdir.

'Namık Kemal Üniv. Ziraat Fak. Bahçe Bitkileri Bölümü-Tekirdağ 
Erik meyvelerinde tüketici tercihlerini oluşturan başlıca kalite faktörlerini suda çözünebilir kuru madde içeriği, titre edilebilir asitlik, suda çözünebilir kuru madde içeriği/ titre edilebilir asitlik oranı, fenolik madde içeriği, meyve eti sertliği ve renk değişimleri belirlemektedir (Crisosto ve Kader 2000). Bu kriterlere göre erik meyvelerinin pazarlanabilir nitelikleri ortaya konulabilmektedir.

Eriklerin muhafaza süresini ve raf ömrünü sınırlayan en önemli faktörler iç yumuşaması ve çürümelerdir. Derim sonrasında farklı uygulamalar ile bu ürünün daha uzun süre muhafazası sağlanabilmektedir.

Taze meyve ve sebzelerde UV-C Işın uygulamaları ürünlerin muhafaza süresini uzatmak bakımından olumlu görülen yeni bir yaklaşımdır (Arul, 1994, Ben-Yehoshua 2003). UV-C Işın uygulaması hasat sonrası ürün kalitesini artırmaya yönelik değil, mevcut kalite özelliklerinin değişimini yavaşlatmaya yönelik bir uygulamadır.

UV-C uygulamalarının etkinliği ürünün çeşidine, olgunluk düzeyine, uygulama dozuna ve süresine bağlı olarak değişmekle birlikte meyvelerde içsel etilen sentezini baskı altına alarak olgunlaşmayı yavaşlatmakta ( Stevens ve ark. 2004, Charles ve ark. 2005) ve patojenlere karşı direnç sağlamaktadır (Cantos ve ark. 2001, Shama ve Alderson 2005). Yapılan araştırmalar sonucunda UV-C ışınlarının elmalarda (Liu ve ark. 1991), domateslerde (Maharaj ve ark. 1999), portakallarda (D'hallewing ve ark. 1999), mangolarda (Gonzalez-Aguilar ve ark. 2001) şeftalilerde (Gonzalez-Aguilar ve ark. 2004) olgunlaşmayı geciktirdiği belirlenmiştir.

UV-C ışınlarının meyve ve sebzelerin depo çürüklüklerinin kontrolü, patojenlerin DNA yapısına verdiği zarardan dolayı öldürücü etkisi ve patojenlere karşı meyve kabuğunda direnç sağlayacak antimikrobiyal bileşiklerin birikimini teşvik etmesi ile ortaya çıkmaktadır (Stevens ve ark. 1996, Marquenie ve ark. 2002).

Bu araștırma ile erik meyvelerinde, farklı dozlarda UV-C uygulamaları sonucu muhafaza süresince meyve kalite özelliklerinin korunmasında en iyi etkiy sağlayacak doz seçimi yapılacaktır.

\section{Materyal ve Yöntem}

2006 yılında yürütülen bu araştırmada kullanılan Giant erik çeşidi Tekirdağ Bağcılık Araştırma Enstitü bahçesinden temin edilmiş ve Namık Kemal Üniversitesi Ziraat Fakültesi Bahçe Bitkileri Bölümüne ait soğuk hava deposunda muhafaza edilmiştir.
Erik meyveleri meyve eti sertliği $4 \mathrm{~kg}$, suda çözünebilir kuru madde miktarı \% 13, titre edilebilir asit miktarı \% 1.20 ve pH değeri 3.19 iken hasat edilmiştir. Hasat edilen meyveler hemen laboratuara taşınarak UV-C ışın uygulamaları yapılmıştır.

UV-C ışığı uygulamasında her biri $2.5 \mathrm{~cm}$ çapında, $88 \mathrm{~cm}$ uzunluğunda, $30 \mathrm{~W}$ çıkışlı, $253.7 \mathrm{~nm}$ dalga boyunda ışık veren, 3 lamba (Philips-Holland) kullanılmıştır. Uygulama kabininin üst kısmına $15 \mathrm{~cm}$ aralıklarla yerleştirilen lambaların ışı yayma alanı $60 \times 100 \mathrm{~cm}$ 'dir. Eriklere $50 \mathrm{~cm}$ ve $100 \mathrm{~cm}$ mesafeden 5 , 10 ve $20 \mathrm{dk}$ süreler ile UV-C ışın uygulaması yapılmıştır (Nigro ve ark. 1998). Kontrol grubuna ışın uygulaması yapılmamıştır. Işın uygulaması sonrasında erikler 750 g'lık kaplar içerisinde $10.5 \mu$ kalınlığındaki polietilen torbalar ile ambalajlanmıştır. Tüm paketler 0$1^{0} \mathrm{C}$ sıcaklık ve $\% 90 \pm 5$ nispi neme sahip depoda 5 hafta süre ile muhafaza edilmiştir ve muhafaza süresince 7 günde bir meyve örneklerinde aşağıda belirtilen ölçümler yapılmıştır.

Ağrılık Kaybı: Meyveler 0.01 g'a duyarlı dijital bir terazi ile tartılmış ve sonuçlar \% olarak hesaplanmıştır.

Meyve Eti Sertliği: El penetrometresi ile ölçülmüş ve sonuçlar kg olarak belirlenmiştir.

Suda Çözünebilir Kuru Madde Miktarı (SÇKM): Refraktometre ile ölçülmüş ve sonuçlar \% şeklinde verilmiştir

Titre Edilebilir Asit Miktarı (TEA): Titrimetrik yöntemle malik asit cinsinden \% olarak hesaplanmıştır.

SÇKM / TEA oranı: SÇKM değerinin TEA değerine bölünmesi ile elde edilmiştir.

pH ölçümü: Dijital pH metre ile ölçümler yapılmıştır.

Duyusal Analiz: Meyvelerin duyusal analizleri 5 kişiden oluşan bir panelist grubu tarafından 1-5 skalası ( 1: çok kötü, 2: kötü, 3: orta 4: iyi 5: çok iyi ) esas alınarak yapılmıştır.

Deneme tesadüf blokları deneme desenine göre 3 tekerrürlü olarak kurulmuş ve her tekerrürde 3 adet paket yer almıştır. Veriler TARIST istatistik programı kullanılarak değerlendirilmiştir.

\section{Bulgular ve Tartışma}

Ağırlık kaybı: Hasat sonrası meyve ve sebzelerin muhafaza süresini kısaltan en önemli faktörlerden birisi ağırlık kaybıdır. Eriklerde meydana gelen ağırlık kayıpları muhafaza süresinin uzamasıyla artış göstermekle birlikte, bazı UV-C dozlarının ve meyvelerin ambalajlanmasının ağırlık kayıplarını 

Muhafazası Üzerine Etkileri

yavaşlattığı görülmüştür. Uygulamalar içerisinde

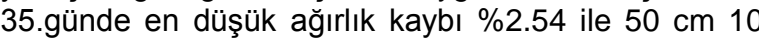
dak UV-C dozunda görülmüş, en yüksek ağırlık kaybı ise \%3.12 ile $100 \mathrm{~cm} 20$ dak UV-C dozunda tespit edilmiş olup bunu kontrol (\%3.00) ve $50 \mathrm{~cm} 20$ dak (\%3.00) uygulaması izlemiştir (Çizelge 1).

Çalışmamız sonuçlarına benzer şekilde, farklı meyve türleri üzerinde yapılan çalışmalarda da UV-C uygulaması yapılan meyvelerde kontrole göre daha az ağırlık kaybı meydana geldiği tespit edilmiş olmakla beraber (Akbudak ve ark. 2002, Maharaj ve ark. 1999), yüksek dozda uygulanan bir UV-C uygulamasının daha düşük dozdaki bir uygulamaya göre daha kötü sonuçlar verebildiğini gösteren araştırmalarda mevcuttur (Wilson ve ark. 1994; Stevens ve ark. 1998).

Meyve Eti Sertliği: Eriklerin muhafazası sırasında uygulamalara göre değişmekle birlikte meyve eti sertliğinde azalmalar meydana gelmiştir. Lippert ve
Blanke (2004)'de muhafaza süresinin uzaması ile birlikte erik meyve eti sertliğinde azalmalar meydana geldiğini belirtmektedir.

Aşırı olgunlaşmanın en önemli belirtilerinden birisi de meyve etinin yumuşamasıdır. Yapılan çalışmada UV-C dozlarının uygulama etkisi incelendiğinde en yüksek meyve eti sertliği değeri $2.52 \mathrm{~kg}$ ile $50 \mathrm{~cm} 10$ dak UV-C dozunda belirlenmiştir. 35. gün sonunda en düşük meyve eti sertliği değeri $0.5 \mathrm{~kg}$ ile kontrol ve 100 $\mathrm{cm} 20$ dak UV-C dozunda görülmüştür (Çizelge 2). Muhafaza sonunda UV-C uygulamalarının $100 \mathrm{~cm} 20$ dak dozu hariç diğer ışın uygulamalarının kontrol meyvelerine göre meyve eti sertliğini korumada daha etkili olduğu tespit edilmiştir. Gonzalez-Aguilar ve ark. (2004)'nın şeftalilerde, Marquenie ve ark. (2005)'nın çileklerde ve Liu ve ark. (1993)'nın de domates meyveleri üzerinde yaptıkları çalışmada da UV-C uygulanmış meyvelerin kontrol meyvelerine göre daha sert oldukları bildirilmiştir.

Çizelge 1. Farklı UV-C dozlarının erik muhafazasında ağılık kaybı (\%) üzerine etkileri

\begin{tabular}{clcccccc} 
& & $\mathbf{7 . g u ̈ n}$ & $\mathbf{1 4 . g u ̈ n}$ & $\mathbf{2 1 . g u ̈ n}$ & $\mathbf{2 8 . g u ̈ n}$ & 35.gün & Uygulama Etkisi \\
\hline \multirow{2}{*}{ Kontrol } & & 0.54 & 0.91 & 1.48 & 2.10 & 3.00 & $1.61 \mathrm{cde}$ \\
& $\mathbf{5}$ dak & 0.53 & 0.79 & 1.29 & 1.93 & 2.68 & $1.44 \mathrm{ab}$ \\
$\mathbf{5 0} \mathbf{~ c m}$ & $\mathbf{1 0} \mathbf{~ d a k}$ & 0.45 & 0.78 & 1.18 & 1.84 & 2.54 & $1.35 \mathrm{a}$ \\
& $\mathbf{2 0} \mathbf{~ d a k}$ & 0.59 & 1.03 & 1.51 & 2.26 & 3.00 & $1.67 \mathrm{de}$ \\
& $\mathbf{5}$ dak & 0.50 & 0.93 & 1.39 & 2.02 & 3.06 & $1.58 \mathrm{~cd}$ \\
$\mathbf{1 0 0} \mathbf{~ c m}$ & $\mathbf{1 0}$ dak & 0.49 & 0.84 & 1.31 & 2.00 & 2.78 & $1.49 \mathrm{bc}$ \\
& $\mathbf{2 0}$ dak & 0.66 & 0.99 & 1.48 & 2.41 & 3.12 & $1.73 \mathrm{e}$ \\
\hline \multicolumn{2}{l}{ Zaman Etkisi } & $0.54 \mathrm{a}$ & $0.89 \mathrm{~b}$ & $1.37 \mathrm{c}$ & $2.08 \mathrm{~d}$ & $2.88 \mathrm{e}$ & \\
\hline
\end{tabular}

$\mathrm{p}<0.05 \quad$ LSD $_{\text {uygulama }}: 0.129 \quad$ LSD $_{\text {zaman }}: 0.109$

Çizelge 2. Farklı UV-C dozlarının erik muhafazasında meyve eti sertliği $(\mathrm{kg})$ üzerine etkileri

\begin{tabular}{|c|c|c|c|c|c|c|c|}
\hline & & 7.gün & 14.gün & 21.gün & 28.gün & 35.gün & Uygulama Etkisi \\
\hline \multirow[t]{2}{*}{ Kontrol } & & 3.00 & 2.53 & 1.83 & 1.23 & 0.50 & $1.82 \mathrm{c}$ \\
\hline & 5 dak & 3.56 & 3.03 & 2.43 & 1.80 & 1.40 & $2.44 \mathrm{ab}$ \\
\hline \multirow[t]{3}{*}{$50 \mathrm{~cm}$} & 10 dak & 3.46 & 3.13 & 2.53 & 1.93 & 1.53 & $2.52 \mathrm{a}$ \\
\hline & 20 dak & 3.06 & 2.60 & 1.90 & 1.20 & 0.66 & $1.88 \mathrm{c}$ \\
\hline & 5 dak & 2.96 & 2.53 & 1.73 & 1.40 & 0.83 & $1.89 \mathrm{c}$ \\
\hline \multirow[t]{2}{*}{$100 \mathrm{~cm}$} & 10 dak & 3.23 & 2.80 & 2.20 & 1.80 & 1.50 & $2.30 \mathrm{~b}$ \\
\hline & 20 dak & 3.13 & 2.76 & 1.80 & 1.50 & 0.50 & $1.94 \mathrm{c}$ \\
\hline \multicolumn{2}{|c|}{ Zaman Etkisi } & $3.22 \mathrm{a}$ & $2.77 \mathrm{~b}$ & $2.08 \mathrm{c}$ & $1.57 \mathrm{~d}$ & $0.99 \mathrm{e}$ & \\
\hline
\end{tabular}


Çizelge 3. Farklı UV-C dozlarının erik muhafazasında SÇKM miktarı (\%) üzerine etkileri

\begin{tabular}{|c|c|c|c|c|c|c|c|}
\hline & & 7.gün & 14.gün & 21.gün & 28.gün & 35.gün & Uygulama Etkisi \\
\hline \multirow[t]{2}{*}{ Kontrol } & & 13.70 & 14.43 & 15.10 & 14.70 & 15.66 & $14.72 a b$ \\
\hline & 5 dak & 13.23 & 14.00 & 14.46 & 14.30 & 15.03 & $14.20 \mathrm{c}$ \\
\hline \multirow[t]{3}{*}{$50 \mathrm{~cm}$} & 10 dak & 13.30 & 13.86 & 14.63 & 14.30 & 15.00 & $14.22 \mathrm{c}$ \\
\hline & 20 dak & 13.90 & 14.13 & 15.03 & 15.30 & 15.76 & $14.82 \mathrm{a}$ \\
\hline & 5 dak & 14.43 & 13.96 & 14.56 & 15.36 & 15.56 & $14.78 \mathrm{ab}$ \\
\hline \multirow[t]{2}{*}{$100 \mathrm{~cm}$} & 10 dak & 13.63 & 14.00 & 14.46 & 15.03 & 15.13 & $14.45 \mathrm{bc}$ \\
\hline & 20 dak & 14.20 & 14.63 & 15.20 & 15.00 & 15.80 & $14.96 \mathrm{a}$ \\
\hline \multicolumn{2}{|c|}{ Zaman Etkisi } & $13.77 \mathrm{~d}$ & $14.14 \mathrm{c}$ & $14.78 \mathrm{~b}$ & $14.85 \mathrm{~b}$ & $15.42 \mathrm{a}$ & \\
\hline
\end{tabular}

Çizelge 4. Farklı UV-C dozlarının erik muhafazasında TEA miktarı (\%) üzerine etkileri

\begin{tabular}{|c|c|c|c|c|c|c|c|}
\hline & & 7.gün & 14.gün & 21.gün & 28.gün & 35.gün & Uygulama Etkisi \\
\hline \multirow[t]{2}{*}{ Kontrol } & & 1.10 & 1.12 & 1.06 & 0.90 & 0.74 & $0.98 \mathrm{c}$ \\
\hline & 5 dak & 1.19 & 1.14 & 1.06 & 1.06 & 0.92 & $1.07 \mathrm{a}$ \\
\hline \multirow[t]{3}{*}{$50 \mathrm{~cm}$} & 10 dak & 1.22 & 1.15 & 1.10 & 1.02 & 0.88 & $1.07 \mathrm{a}$ \\
\hline & 20 dak & 1.08 & 1.10 & 1.02 & 0.97 & 0.74 & $0.98 \mathrm{c}$ \\
\hline & 5 dak & 1.11 & 1.10 & 1.03 & 0.97 & 0.84 & $1.01 \mathrm{bc}$ \\
\hline \multirow[t]{2}{*}{$100 \mathrm{~cm}$} & 10 dak & 1.14 & 1.10 & 1.05 & 1.05 & 0.85 & $1.04 \mathrm{ab}$ \\
\hline & 20 dak & 1.07 & 1.09 & 1.00 & 1.00 & 0.73 & $0.98 c$ \\
\hline \multicolumn{2}{|c|}{ Zaman Etkisi } & $1.13 \mathrm{a}$ & $1.11 \mathrm{a}$ & $1.04 \mathrm{~b}$ & $0.99 \mathrm{c}$ & $0.82 \mathrm{~d}$ & \\
\hline
\end{tabular}

SÇKM: Muhafaza süresince eriklerin SÇKM miktarlarında değişen oranlarda dalgalanmalar görülmekle birlikte genel olarak hasat dönemine göre daha yüksek değerlere ulaşmıştır. Taze ürünlerin soğukta muhafazası sırasında SÇKM miktarındaki artışın nedeni, su kaybı sonucu şekerlerin meyve suyunda oransal olarak artması veya şekerlerin mutlak artışı da olabilir (Özdemir ve ark. 2005). Türk ve ark. (1995)'da çalışmalarında eriklerin SÇKM değişimlerinin muhafaza süresince önemli miktarda artış gösterdiğini belirlemişlerdir.

Araştırmada uygulama etkileri incelendiğinde en yüksek SÇKM miktarı $100 \mathrm{~cm} 20$ dak dozu (\%14.96) ve $50 \mathrm{~cm} 20$ dak dozunda (\%14.82), en düşük SÇKM değeri ise $50 \mathrm{~cm} 5$ dak (\%14.20) ve 10 dak (\%14.22) dozunda belirlenmiştir (Çizelge 3). Yapılan UV-C uygulamalarının SÇKM miktarındaki değişimler üzerine düzenli bir etki yaptığı tespit edilememiştir. Özer ve Akbudak (2003) ve Taira ve ark. (1997)'nın yaptıkları çalışmada da UV-C uygulaması yapılan ürünlerde SÇKM değişimlerinin çok fazla belirgin olmadığı tespit edilmiştir.

TEA miktarı ve pH: Araştırmada genel olarak muhafaza süresince TEA miktarında azalmalar ve $\mathrm{pH}$ değerinde ise dalgalanmalar ile birlikte artışlar görülmüştür. Özer ve ark. (1999) ve Özkaya ve ark. (2005)'da eriklerin soğukta muhafazasında olgunluğun artması ile birlikte TEA miktarında azalmaların, $\mathrm{pH}$ değerinde de artışların olduğunu belirtmektedir. Uygulama etkileri incelendiğinde TEA değerinin en az ve dolayısıyla olgunlaşmanın en yüksek olduğu meyveler ise, kontrol, $50 \mathrm{~cm} 20$ dak ve $100 \mathrm{~cm} 20$ dak UV-C uygulamalarında tespit edilmiştir (Çizelge 4). Benzer sonuçlar Akbudak ve Karabulut (2002), Özer ve Akbudak (2003)'ın üzüm üzerine uygulamalarında elde edilmiştir.

Denemede bütün uygulamalarda, muhafaza sonunda hasat değerine göre (3.19) pH değerinde artış olduğu belirlenmiştir (Çizelge 5). Uygulamalar içerisinde en hızı ırtış $100 \mathrm{~cm} 20$ dak uygulamasında tespit edilmiştir.

SÇKM/TEA Oranı: Eriklerde SÇKM/TEA oranı tüketici tercihlerini oluşturan kalite faktörlerinden biridir (Crisosto ve Kader, 2000) ve bu oran arttıkça eriklerde olgunluğun arttığı görülür. Crisosto ve ark. (2004)'nın eriklerde tüketici tercihleri ile ilgili yaptıkları çalışmada erken hasat edilen meyvelerde SÇKM/TEA oranın düşük, daha geç hasat edilen olgun eriklerde ise yüksek olduğu belirlenmiştir. Benzer şekilde çalışmamızda da hasat döneminde yüksek asitlik ve 
nispeten düşük SÇKM değerleri nedeniyle 10.83 olan SÇKM/TEA oranı uygulamalara da bağlı olarak muhafaza sonunda artış göstermiştir. Araştırma sonucunda 35. günde en yüksek SÇKM/TEA oranı 100 cm 20 dak (21.65) uygulamasında, en düşük SÇKM/TEA oranı ise $50 \mathrm{~cm} 5$ dak (16.34) UV-C uygulamasında belirlenmiştir (Çizelge 6 ). Bu sonuçlar neticesinde UV-C dozlarının bazılarının olgunluğu yavaşlatarak SÇKM/TEA oranının düşük kalmasına sebep olduğu tespit edilmiştir.
Duyusal analiz : 5 kişilik panelist tarafından tat ve dış görünüşüne bağlı olarak yapılan duyusal analizde, 35. gün sonunda pazarlanamaz nitelikte en düşük puanı $100 \mathrm{~cm} 5$ dak (2.16) ve 20 dak (2.83) UV$\mathrm{C}$ dozu ile kontrol grubu (2.63) almıştır (Çizelge 7). Bu grupta yer alan meyvelerde çürüme ve renkte matlaşma tespit edilmiştir. Bu uygulamalar dışında kalan UV-C uygulamalar ise ışınların olgunlaşmayı yavaşlatması ve çürümeleri engellemesinin etkisiyle pazarlanabilir niteliklerini korumuştur.

Çizelge 5. Farkı UV-C dozlarının erik muhafazasında pH miktarı üzerine etkileri

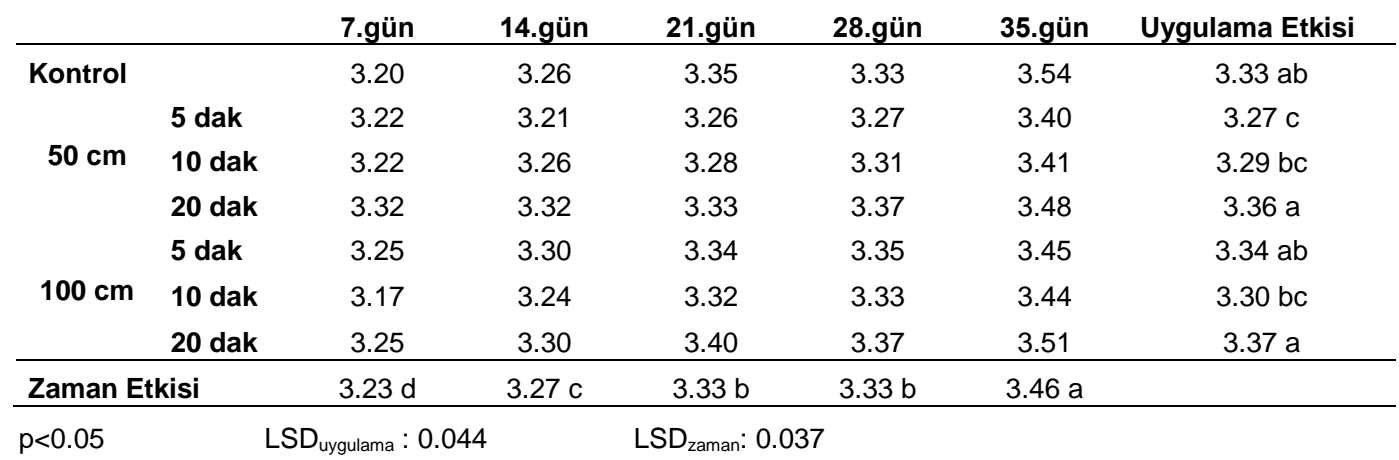

Çizelge 6. Farklı UV-C dozlarının erik muhafazasında SÇKM/TEA oranı üzerine etkileri

\begin{tabular}{|c|c|c|c|c|c|c|c|}
\hline & & 7.gün & 14.gün & 21.gün & 28.gün & 35.gün & Uygulama Etkisi \\
\hline \multirow[t]{2}{*}{ Kontrol } & & $12.50 \mathrm{n}-\mathrm{q}$ & 12.30 o-r & 14.25 h-m & 15.63 e-h & $20.07 b$ & $14.95 \mathrm{bc}$ \\
\hline & 5 dak & $10.46 \mathrm{~s}$ & 12.28 o-r & 13.65 I-0 & $13.45 j-p$ & 16.34 def & $13.23 \mathrm{f}$ \\
\hline \multirow[t]{3}{*}{$50 \mathrm{~cm}$} & 10 dak & $10.87 \mathrm{rs}$ & 11.99 prs & $13.31 \mathrm{k}-\mathrm{q}$ & 14.03 I-n & 16.94 cde & 13.43 ef \\
\hline & 20 dak & $12.80 \mathrm{l}-\mathrm{q}$ & $12.81 \mathrm{l-q}$ & $14.74 \mathrm{~g}-\mathrm{k}$ & 15.68 e-h & $21.20 \mathrm{ab}$ & $15.45 a b$ \\
\hline & 5 dak & $12.54 n-q$ & $12.69 \mathrm{~m}-\mathrm{q}$ & 14.06 I-n & $15.87 \mathrm{efg}$ & $18.41 \mathrm{c}$ & $14.71 \mathrm{~cd}$ \\
\hline \multirow[t]{2}{*}{$100 \mathrm{~cm}$} & 10 dak & 11.88 qrs & $12.66 n-q$ & 13.78 I-0 & $14.31 \mathrm{~g}-\mathrm{I}$ & $17.77 \mathrm{~cd}$ & $14.08 \mathrm{de}$ \\
\hline & 20 dak & $13.25 \mathrm{k}-\mathrm{q}$ & $13.44 j-q$ & $15.20 \mathrm{f}-\mathrm{I}$ & $14.90 \mathrm{f}-\mathrm{j}$ & $21.65 \mathrm{a}$ & $15.69 \mathrm{a}$ \\
\hline \multicolumn{2}{|c|}{ Zaman Etkisi } & $12.04 \mathrm{~d}$ & $12.59 \mathrm{~d}$ & $14.14 \mathrm{c}$ & $14.84 \mathrm{~b}$ & $18.91 \mathrm{a}$ & \\
\hline$<0.05$ & $\mathrm{LSD}_{\text {uygul }}$ & $\operatorname{man}: 1.567$ & & LSD $_{\text {uygulama }}$ & 99 & $\mathrm{LSD}_{\text {zam }}$ & 591 \\
\hline
\end{tabular}

Çizelge 7. Farklı UV-C dozlarının erik muhafazasında duyusal analiz puanı üzerine etkileri

\begin{tabular}{|c|c|c|c|c|c|c|c|}
\hline & & 7.gün & 14.gün & 21.gün & 28.gün & 35.gün & Uygulama Etkisi \\
\hline \multirow[t]{2}{*}{ Kontrol } & & 3.36 I-I & $4.06 \mathrm{~d}-\mathrm{g}$ & $4.60 \mathrm{ab}$ & $3.56 \mathrm{~h}-\mathrm{k}$ & $2.63 n$ & $3.64 b c$ \\
\hline & 5 dak & $3.43 \mathrm{I}$ & $3.73 \mathrm{f}-\mathrm{I}$ & $4.33 \mathrm{a}-\mathrm{e}$ & $4.53 \mathrm{abc}$ & 4.00 e-h & $4.00 \mathrm{a}$ \\
\hline \multirow[t]{3}{*}{$50 \mathrm{~cm}$} & 10 dak & $3.20 \mathrm{klm}$ & $3.60 \mathrm{~g}-\mathrm{k}$ & $4.50 \mathrm{a}-\mathrm{d}$ & $4.60 a b$ & $4.13 c-f$ & $4.00 \mathrm{a}$ \\
\hline & 20 dak & $3.26 \mathrm{j}-\mathrm{m}$ & $4.06 \mathrm{~d}-\mathrm{g}$ & $4.76 \mathrm{a}$ & $3.66 \mathrm{~g}-\mathrm{k}$ & $3.06 \mathrm{Imn}$ & $3.76 \mathrm{~b}$ \\
\hline & 5 dak & $3.26 \mathrm{j}-\mathrm{m}$ & $4.20 \mathrm{~b}-\mathrm{e}$ & $4.73 \mathrm{a}$ & $3.23 \mathrm{klm}$ & 2.160 & $3.52 \mathrm{c}$ \\
\hline \multirow[t]{2}{*}{$100 \mathrm{~cm}$} & 10 dak & $3.56 \mathrm{~h}-\mathrm{k}$ & $4.00 \mathrm{e}-\mathrm{h}$ & $4.53 a b c$ & 4.33 a-e & $3.70 \mathrm{f}-\mathrm{j}$ & $4.02 \mathrm{a}$ \\
\hline & 20 dak & $3.73 \mathrm{f}-\mathrm{I}$ & 4.40 a-e & $4.26 \mathrm{~b}-\mathrm{e}$ & $3.96 \mathrm{e}-\mathrm{h}$ & $2.83 \mathrm{mn}$ & $3.84 a b$ \\
\hline \multicolumn{2}{|c|}{ Zaman Etkisi } & $3.40 \mathrm{c}$ & $4.01 \mathrm{~b}$ & $4.53 \mathrm{a}$ & $3.98 b$ & $3.21 \mathrm{~d}$ & \\
\hline
\end{tabular}




\section{Sonuç}

Sonuç olarak, UV-C uygulamalarında optimum düzeyde fayda sağlayabilmek için, uygulamanın yapıldığı ürünlerin yapısında olumsuzluklar yaratmayacak dozların kullanılması gerekmektedir. Araştırmamızda UV-C uygulamalarının bazı dozlarının, meyvelerde kalite değişimlerini sınırlandırarak muhafaza süresince çok fazla bir değişim meydana getirmeden istenen seviyelerde kalmasını sağlanmıştır. UV-C uygulamasının özellikle $50 \mathrm{~cm} 5$ dak ve 10 dak UV-C dozlarının eriklerin muhafazasında daha etkili olacağı ve kontrole göre muhafaza süresini 1 hafta daha uzatabildiği tespit edilmiştir.

\section{Kaynaklar}

Anonymous 2005. www.fao.org (10.06.07).

Arul, J. 1994. Emerging technologies for the control of postharvest diseases of fresh fruits and vegetables. In: C.L. Wilson and M.E. Wisniewski (eds.), Biological control of post harvest diseases-theory and practice. CRC Press, Boca-Raton, FL.

Akbudak, B. ve Ö.A. Karabulut. 2002. Üzüm Muhafazasında Gri Küf'den (Botrytis cinerea Pers:Fr.) Kaynaklanan Kalite Kaybı ve Çürümelerin Ultraviolet-C (UV-C) Işık Uygulamaları ile Önlenmesi Üzerine Bir Araștırma. Ulud. Üniv. Zir. Fak. Derg., 16(2): 35-46.

Ben-Yeshohua, S. 2003. Effect of post-harvest heat and UV applications on decay, chilling injury and resistance against pathogens of citrus and other fruits and vegetable. Acta Hort., 599: 159-173.

Cantos, E., J. C. Espin and F. A. Tomas-Barberan. 2001. Postharvest induction modeling method using UV irradiation pulses for obtaining resveratrol-enriched table grapes: A new 'functional' fruit? Journal of Agricultural and Food Chemistry 49: 5052-5058.

Charles, M.T., Kalantari, R., R. Corcuff and J. Arul. 2005. Postharvest quality and sensory evaluation of UVtreated tomato fruit. Acta Hort., 682: 537-542.

Crisosto, C.H. and A.A. Kader. 2000. Plum and fresh prune postharvest quality. maintenance guidelines. www.uckac.edu/postharv/PDF\%20files/plum.pdf

Crisosto, C.H., D. Garner, G.M. Crisosto and E. Bowerman. 2004. Increasing 'Blackamber' plum (Prunus salicina Lindell) consumer acceptance, Postharvest Biol. Technol., 34: 237-244.

D'hallewin, G., Schirra, M., Manueddu, E., A. Piga and S. Ben-Yehoshua. 1999. Scoparone and scopaletin accumulation and ultraviolet- $C$ induced resistance to postharvest decay in oranges as influenced by harvest date. Journal of the American Society of Horticultural Science 124: 702-707.
Eriş, A. 2001. Türkiye'de sert çekirdekli meyvelerin muhafaza potansiyeli ve hedefler. I. Sert Cekirdekli Meyveler Sempozyumu,25-28 Eylül, Yalova. 17-28.

Gonzalez-Aguilar, G. A., Wang, C. Y., J. G. Buta and D. T. Krizek. 2001. Use of UV-C irradiation to prevent decay and maintain postharvest quality of ripe 'Tommy Atkins' mangoes. International Journal of Food Science and Technology 36: 767-773.

González-Aguilar, G.A., C. Y. Wang and J. G. Buta. 2004. UV-C irradiation prevents breakdown and chilling injury of peaches during cold storage. Journal of the Science of Food and Agriculture 84(5):415-422.

Kim, D.O., Chun, O.K., Kim, Y.J., H.Y. Moon and C.Y. Lee. 2003. Quantification of polyphenolics and their antioxidant capacity of fresh plums. J. Agric. Food Chem., 51: 6509-6515.

Lippert, F. and M.M. Blanke. 2004. Effect of mechanical harvest and timing of 1-MCP application on respiration fruit quality of european plums. Postharvest Biology and Technology 34: 305-311.

Liu, J., Stevens, C., V.A Khan and M. Kabwe. 1991. The effect of ultraviolet irradiation on shelf-life and ripening of peaches and apples. Journal of Food Quality 14: 299-305.

Liu, J., Stevens, C., Khan, V. A., Lu, J. Y., C. L. Wilson and O. Adeyeye. 1993. Application of ultraviolet-c light on storage rots and ripening of tomatoes. Journal of Food Protection, 56: 868-872.

Maharaj, R., J. Arul and P. Nadeau. 1999. Effect of photochemical treatment in the preservation of fresh tomato (Lycopersicon esculentum cv. Capello) by delaying senescence. Postharvest Biology and Technology 15 (1): 13-23.

Marquenie, D., Nicolai, B. M., Impe, J. F. van, Michiels, C. W., Geeraerd, A. H., A. Schenk and C. Soontjens. 2002. Using survival analysis to investigate the effect of UV-C and heat treatment on storage rot of strawberry and sweet cherry. International Journal of Food Microbiology 73: 187-196.

Marquenie, D., J. Lammertyn and B.M. Nicolai. 2005. UV-C as Postharvest Treatment in Small Fruits. In: The Use of UV-C as a Postharvest Treatment: Status and Prospects (edited by COST Action 924 Working Group Meeting).Pp. 44-48. Antalya, Turkey.

Nigro, F., A. Ippolitto and G. Lima. 1998. Use of UV-C light to reduce Botrytis storage rot of table grapes. Postharvest Biol. Technol., 13: 171-181.

Özçağıran, R., Ünal, A., E. Özeker ve M. İsfendiyaroğlu. 2003. Ilıman iklim meyve türleri: Sert çekirdekli meyveler, Cilt 1. Ege Üniv. Zir. Fak. Yayınları, No:553. 
Özer, M.H., A. Eris ve B. Akbudak. 1999. Bazı erik çeșitlerinin modifiye atmosferde muhafazası üzerine bir araştırma. Türkiye III. Ulusal Bahçe Bitkileri Kongresi. 162-166 Ankara

Özer, M.H. ve B. Akbudak. 2003. Doğal ve Yapay Gri Küf (Botrytis cinerea Pers:Fr.) Bulaşık Olan Üzümlerin Muhafazası Üzerine Ultraviolet-C (UV-C) Işık Uygulamalarının Etkisi. Ulud. Üniv. Zir. Fak. Derg., 17(2): 23-32

Özdemir, A.E., Ertürk, E., M. Çelik, ve R. Dilbaz. 2006. Venüs nektarin çeşidinin soğukta muhafazası. Tekirdağ Ziraat Fakültesi Dergisi 3(3): 297-304.

Özkaya, O., Ö. Dündar ve A. Küden. 2005. adana koşullarında yetiştirilen Angelino erik çeşidinin muhafaza performansı. III. Bahçe Ürünlerinde Muhafaza ve Pazarlama Sempozyumu, Antakya. 406-408.

Perez-Gago, M.B., C. Rojas and M.A. Del Rio. 2003. Effect of Hydroxypropyl Methylcellulose-Lipid Edible Composite Coatings on Plum (cv. Autumn giant) Quality During Storage. Journal of Food Science 68 (3): 879-883.

Shama G. and P. Alderson. 2005. UV hormesis in fruits: a concept ripe for commercialization. Trends in Food Science and Technology. 16: 128-136.

Stevens, C., Wilson, C., Lu., J. Y.L., Khan, V. A., Chalutz, E., Droby, S., Kabwe, M.K., Haung, Z., Adeyeye, O., Pusey, L.P., M.E. Wisniewski and M. West. 1996. Plant hormesis induced by ultraviolet light-C for controlling postharvest diseases of tree fruits. Crop Protection, 15(2): 129-134.
Stevens, C., Khan,V.A., Lu,J.Y., Wilson, C.L. Pusey, P.L., Igwegbe, E.C.K. Kabwe, K., Mafola, Y., Liu, J., E. Chalutz and S. Droby. 1998. Integration of Ultraviolet (UV-C) Light with Yeast Treatment for Control of Postharvest Storage Rots of Fruits and Vegetables. Postharvest News and Information 9 (6): 2792

Stevens, C., Liu, J., Khan, V.A., Lu, J.Y., Kabwe, M.K.,Wilson, C.L., Igwegbe, E.C.K., E. Chalutz and S. Droby. 2004. The effects of low-dose ultraviolet light- $C$ treatment on polygalacturonase activity, delay ripening and Rhizopus soft rot development of tomatoes. Crop Protection 23: $551-554$

Taira, S., E. Kato, and S. Watonabe. 1997. Effects of on Tree and Postharvest UV Irradiation on Coloration in Sweet Cherry Fruit. Postharvest News and Information 8 (3): 1115.

Türk, R., K. Koçak ve B.Akbudak. 1995. Eriklere modifiye atmosferin muhafaza süresine etkisi üzerine bir araştırma. Türkiye 2. Ulusal Bahçe Bitkileri Kongresi, 203-208 Adana..

Wilson, C.L., Ghaouth, A., Chalutz, El E., Droby, S., Stevens, C., Lu, J.L., V. Khan and J. Arul. 1994. Potential of Induced Resistance to Control Postharvest Diseases of Fruits and Vegetables. Plant Disease 78: 837-844.

\section{İletişim Adresi:}

Erdinç BAL

Namık Kemal Üniversitesi Ziraat Fakültesi

Bahçe Bitkileri Bölümü-Tekirdağ

Tel: 03805421137 